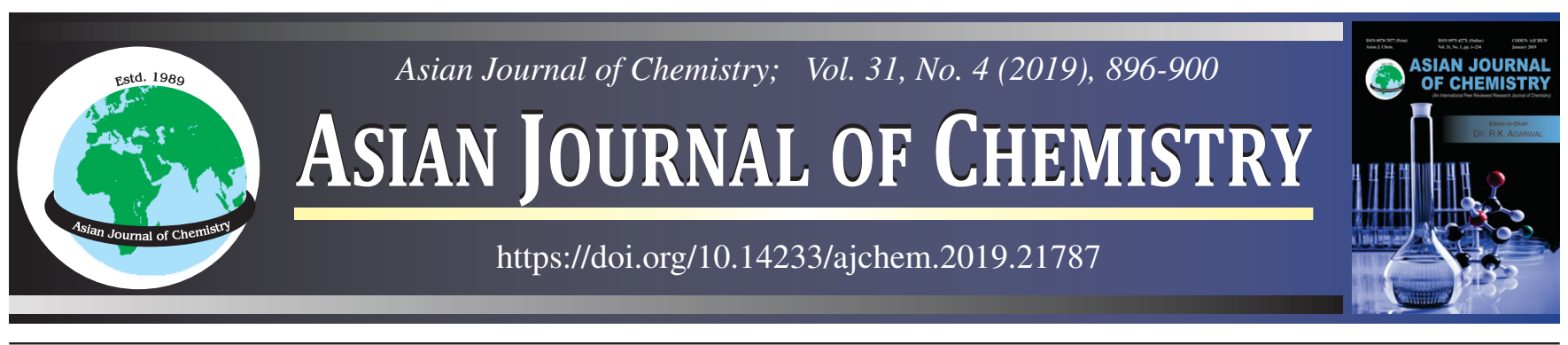

\title{
A Rapid Thin Layer Chromatographic Method for Simultaneous Screening of Albendazole and Ivermectin in Formulations Prescribed for Human or Veterinary Use
}

\author{
R.P. PAWAR ${ }^{1}$, P. Mishra ${ }^{2}$, A. DurgBanshi ${ }^{2}$ and D. Bose ${ }^{1, *}$
}

${ }^{1}$ Department of Criminology and Forensic Science, Dr. Harisingh Gour Vishwavidyalaya (A Central University), Sagar-470003, India ${ }^{2}$ Department of Chemistry, Dr. Harisingh Gour Vishwavidyalaya (A Central University), Sagar-470003, India

*Corresponding author: E-mail: devonebose@gmail.com

Received: 30 October 2018;

Accepted: 7 January 2019;

Published online: 27 February 2019;

AJC-19304

| An easy and selective thin layer chromatographic method has been developed and experimentally validated for the simultaneous screening of most commonly used anthelmintic drugs i.e. albendazole and ivermectin. Separation of these compounds was attained on silica gel 60 $\mathrm{F}_{254}$ pre-coated thin layer chromatographic plate using an optimized mobile phase of diisopropyl ether:ethyl acetate:glacial acetic acid in the ratio of 7:3:0.1 (v/v), respectively at $\mathrm{pH} 3.5$. The calculated $\mathrm{R}_{\mathrm{f}}$ values for albendazole and ivermectin were 0.65 and 0.38 , respectively and the LOD was found to be $25 \mu \mathrm{g} / \mathrm{ml}$ and $30 \mu \mathrm{g} / \mathrm{ml}$ for albendazole and ivermectin, respectively. The developed method is selective, sensitive, robust, cost effective, eco-friendly, rapid as well as easy to perform. The developed method was successfully applied for the analysis of albendazole and ivermectin in pharmaceutical preparations marketed as oral suspensions, powder, tablets and injectable of the single or combined dosage forms for human as well as veterinary use. It could also be applied for the simultaneous analysis of both the compounds in other samples.

Keywords: Anthelmintics, Albendazole, Ivermectin, Simultaneous screening, Thin layer chromatography.

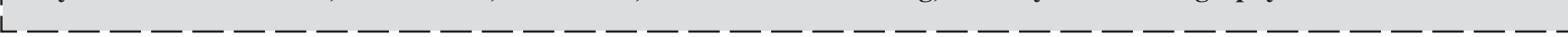

\section{INTRODUCTION}

Broad spectrum anthelmintic agents such as albendazole and ivermectin belong to a benzimidazole and macrocyclic lactone class of drugs, respectively. Among the most commonly used pharmaceutical preparations these are widely used for the treatment of endo or ectoparasitic infections or as a dewormers in veterinary and human being [1-3]. These are available in various dosage forms, either as a single drug or in combination, which are marketed as tablets, bolus, powder, oral suspensions or injections for veterinary uses. For the purpose of human use these drugs are marketed only in the form of tablets and oral suspensions. Generally, albendazole is prescribed as a single drug for the treatment of anthelmintic infections in human and animals. Where as in case of severe infection and for the cause of effective treatment, a combined dose of albendazole and ivermectin is prescribed by the medical practitioners [4]. In case of human use these drugs are prescribed by the doctor but in case of animals, these are frequently given to them without any medical prescription by farmers or cattle rearers. Repeated and irregular doses are normally given to the animals which may causes severe health issues not only to the cattle but also to the end users [5]. Apart from this, if the doses are given to the poultry or lactating animals, the possibility of presence of the residual parent drug or its metabolites in chicken, milk and milk products will also be high [2,6-8].

Single or simultaneous determination of active components of these kind of pharmaceutical preparations using various analytical methods such as spectroscopy [9], high performance thin layer chromatography [10], high performance liquid chromatography $[1,3,7,8,11-13]$, liquid chromatography coupled with mass spectrometers $[2,4,6]$ as well as LC-MS/ MS/MS [14] have been reported for the detection of these drugs in both human and animals [10]. Some researchers have also reported detection and quantification of these drugs or their metabolites in various biological samples or food products derived from animals by using ultra high performance liquid chromatography-tandem mass spectrometry $[15,16]$. All the above mentioned techniques are either expensive or time consuming and requires tedious sample preparation before analysis.

This is an open access journal, and articles are distributed under the terms of the Creative Commons Attribution-NonCommercial-ShareAlike 4.0 (CC BY-NC-SA 4.0) International License which allows readers to freely read, download, copy, distribute, print, search, or link to the full texts of its articles and to use them for any other lawful non-commercial purpose as long as the original source is duly acknowledged. 
Hence, there is an urgent need for the development and validation of a simple, rapid, sensitive and selective method for the screening of these drugs prior to moving on to sophisticated chromatographic instrumentation. Most of the methods reported the detection of single compound only in tablets or solid dosage forms using different chromatographic techniques. No research work has been reported for these two drugs using simple and green thin layer chromatography (TLC). While in the current research work, an attempt has been made to screen, both active components in tablets, oral suspensions, powder and injections using a TLC method.

\section{EXPERIMENTAL}

The standard sample of albendazole (ABZ) and ivermectin (IVM) were procured from Sigma Aldrich-Merck, Bengaluru (India). The random sampling of the pharmaceutical products of Vet Mankind Pharma Ltd. New Delhi (India), Virbac Animal Health India Pvt. Ltd. Mumbai (India), ZEE Laboratories Ltd., Himachal Pradesh (India), Wockhardt Ltd. Mumbai (India), Intas Pharmaceuticals Ltd. Gujarat (India), Sanket Healthcare, Gujarat (India) was done from the local chemist shop. Pre- coated TLC plates (Silica Gel $60 \mathrm{~F}_{254}, 20 \times 20 \mathrm{~cm}$ ) were purchased from E. Merck Ltd. Mumbai (India). All the solvents used for the optimization of the mobile phase i.e. ethyl acetate, hexane, toluene, glacial acetic acid, diisopropyl ether, propanol, butanol and pentanol were of analytical grade and purchased from Qualigens Fine Chemicals, Mumbai (India). The chemicals were weighed using a weighing balance, Mettler Toledo Pvt. Ltd. (India) and dissolved with an ultrasonic bath, PCI Analytics Pvt. Ltd. (Russia). A micropipette (1-10 $\mu \mathrm{L})$ used for the loading of the samples on the TLC plate, was purchased from Tarson, Calcutta (India). The plates were run by using a glass twin trough $(10 \times 10 \mathrm{~cm})$ chromatographic development chamber. A UV-visible cabinet model CRYSTAL 3, Mumbai (India) was used for the visualization of the developed spots.

Standard sample preparation: In order to prepare stock solutions, $1 \mathrm{mg}$ of each standard drugs were dissolved in $10 \mathrm{~mL}$ of methanol followed by $5 \mathrm{~min}$ of ultra-sonication to obtain a concentration of $100 \mathrm{ppm}$. Solutions were stored in $10 \mathrm{~mL}$ amber glass volumetric flask at $4^{\circ} \mathrm{C}$. Finally, all the solutions were filtered through $0.45 \mu \mathrm{m}$ nylon membrane filters and diluted as required.

Pharmaceutical samples preparation: For tablets/ bolusten tablets/bolus of each preparation were weighed accurately then crushed and homogenized by using a pestle and mortar and then taken into a clean recipient, separately. $10 \mathrm{mg}$ of each powdered tablets was dissolved in $2 \mathrm{~mL}$ of pure methanol, which was further diluted to $10 \mathrm{~mL}$ by addition of same solvent. The solutions were sonicated for $5 \mathrm{~min}$ in an ultrasonic bath. Finally, the solutions were filtered through $0.45 \mu \mathrm{m}$ nylon membrane filters and used for further TLC analysis.

Oral suspension: As mentioned above, $1 \mathrm{~mL}$ of each oral suspension was homogenized with $10 \mathrm{~mL}$ of pure methanol in a clean glass test tube followed by 5 min of ultrasonication. Then all the solutions were filtered through Whatman filter papers and the filtrates were used for the analysis.

Injections: Each injections containing ivermectin was directly diluted with absolute methanol to obtain a concentration of $50 \mathrm{ppm}$ and then used for further analysis.
Thin layer chromatographic conditions: Sample application is a key factor for obtaining higher resolution in TLC. Smaller the spot, higher will be the resolution [17]. Hence, 1 $\mu \mathrm{L}$ of $50 \mathrm{ppm}$ strength of each drug was spotted on a precoated TLC plate with the help of a micropipette. The standard samples were spotted $1.5 \mathrm{~cm}$ away from the edge of plate and the distance between two spots were $1 \mathrm{~cm}$. To optimize a suitable mobile phase, various organic solvents were used according to the polarity of analytes and other physico-chemical properties. A clean twin trough chromatographic development chamber made up of glass was used for the development of TLC plate in an ascending mode. The plates were marked up to the distance of $75 \%$ from the sample loading site as a solvent front. The chamber saturation time was $10 \mathrm{~min}$ for each mobile phase. After allowing the solvent to run the marked solvent front, the plate was taken out from the chamber and air dried at room temperature and then visualized under the UV light at $254 \mathrm{~nm}$. Based on the location of the spot $R_{f}$ values were calculated for each analyte.

\section{RESULTS AND DISCUSSION}

Optimization of mobile phase: In order to optimize the best mobile phase for the separation of albendazole and ivermectin, solvents such as water, glacial acetic acid, ethanol, ethyl acetate, propanol, pentanol, toluene, diisopropyl ether were used in decreasing order of their polarity. Water is one of the commonest, universal and eco-friendly solvent generally used in most of the mobile phases. Based on the chemical properties, albendazole and ivermectin are water insoluble. Hence, to verify this fact by TLC, first of all pure water was used as a mobile phase, in which both the compounds did not participate in chromatographic separation and strongly retained on the stationary phase which indicated that the analytes are having $100 \%$ affinity with the stationary phase. It could also be concluded that the selected drugs are not truly polar in nature (Table-1). Likewise, moving on with other solvent like di isopropyl ether where both the compounds were strongly retained by stationary phase verifying the fact that these compounds are not soluble in diisopropyl ether as well. While using other moderately polar solvents like ethanol, pentanol and ethyl acetate the analytes showed chromatographic separation but not remarkable resolution to have an optimum separation and moved almost with the solvent front.

Therefore, to have an optimum separation condition, different combinations of solvents were used. Based on the properties of albendazole and ivermectin, it was decided to slightly acidify the mobile phase which may lead to proper separation. While using ethanol, pentanol and ethyl acetate with less than $10 \%$ of glacial acetic acid, both the compounds showed impressive chromatographic behaviour but again the obtained separation was poor which compelled the use of a solvent in combination to maintain an intermediate polarity. As evident from the initial results that while using individual solvent like ethyl acetate, the spots of albendazole and ivermectin recorded the $R_{\mathrm{f}}$ value of 0.77 and 0.8 , respectively. Using diisopropyl ether, the compounds were retained in the stationary phase. Based on the chromatographic behaviour of selected compounds, the use of a combination of ethyl acetate and diisopropyl ether was decided. Using different combination of both the solvents, 


Compound

marked separation of the analyte was obtained. Better resolution was achieved when the concentration of ethyl acetate was reduced and the concentration of diisopropyl ether was increased. Diisopropyl ether and ethyl acetate in the ratio of 7:3 (v/v) was found to be the best suitable mobile phase for the separation of both analytes. The $\mathrm{R}_{\mathrm{f}}$ value found to be 0.65 and 0.38 for albendazole and ivermectin, respectively. As per another reported fact, addition of a small amount of acid in the mobile phase slightly reduced the binding of the basic molecules with silica gel surface and improves the quality of the spots (fine spots), which leads to a lower detection limits $[18,19]$. Therefore, 0.1 $\mathrm{mL}$ of glacial acetic acid was added in the final solvent system. The improvement in the spot quality is due to the fact that the surface of stationary phase is silica gel containing silanol (Si-OH) groups which act as an acidic moiety. If a basic analyte is present in acidic condition, there will be sufficient protons in mobile phase and basic analyte will become protonated. Since both mobile phase and analytes are protonated their interaction with stationary phase reduces which leads to higher value of $\mathrm{R}_{\mathrm{f}}$. Finally, diisopropyl ether:ethyl acetate:glacial acetic acid in the ratio of 7:3:0.1 (v/v/v) at $\mathrm{pH} 3.5$ was selected as the optimum mobile phase for further analysis of selected analytes in different pharmaceutical samples which showed good separation, better spot profile and distinct resolution.

Chemistry of separation: The $\mathrm{pK}_{\mathrm{a}}$ value of albendazole is 6.9 and so at a pH of 3.5, the molecule will be protonated. It is a well-established fact that if the $\mathrm{pH}$ of mobile phase is less than $\mathrm{pKa}$ of analyte, the analyte will predominate in protonated form. Since the molecule is relatively non-polar and protonated, its interaction with the polar silanol group of the stationary phase will be very less leading to the higher value of $R_{f}$. The second aspect being the non-polar nature of mobile phase and albendazole also being neutral interacts more with the mobile phase and hence high value of $R_{f}$.

The next analyte ivermectin has a pKa value of -3.4 and since the $\mathrm{pH}$ of mobile phase is 3.5 , the negative value of $\mathrm{pKa}$ confirms that ivermectin exists predominantly in dissociated form at a $\mathrm{pH}$ of 3.5 which means that the molecule is negatively charged. The acidic strength of drug is higher than the acidic strength of mobile phase which justifies that the molecule of ivermectin bears a negative charge. Since the stationary phase is polar and the molecule of ivermectin being negatively charged will have more interaction with the polar stationary phase and spending less time with the non-polar mobile phase. Therefore, the $\mathrm{R}_{\mathrm{f}}$ value of ivermectin will be less as compared to albendazole.

Method validation: Some of the parameters like selectivity, limit of detection, repeatability, reproducibility and robustness were evaluated to check the convenience of currently developed method.

Selectivity and limit of detection: Selectivity is one of the most important parameter for the method validation especially in separation science. According to the obtained $R_{f}$ values, the studied compounds were well separated. Therefore, it could be concluded that the developed TLC method has a good selectivity for the simultaneous analysis of albendazole and ivermectin in different pharmaceutical preparations.

For determining LOD, the concentration ranges from 100 $\mu \mathrm{g} / \mathrm{mL}$ to $10 \mu \mathrm{g} / \mathrm{mL}$ of albendazole and ivermectin was applied on the TLC plate by using a micropipette. The minimum concentration which could be spotted under UV-light was $25 \mu \mathrm{g} / \mathrm{mL}$ for albendazole and $30 \mu \mathrm{g} / \mathrm{mL}$ for ivermectin.

Repeatability and reproducibility: The intra and interday repeatability of the method was determined by examining three different concentrations (i.e. 50,75 and $100 \mu \mathrm{g} / \mathrm{mL}$ ) of albendazole and ivermectin for five times on the same day and five different days using the optimum mobile phase and the changes in the $R_{\mathrm{f}}$ valuesof albendazole and ivermectin was calculated. The results shown in Table- 2 indicate good repeatability of the developed TLC method.

In order to perform reproducibility study, inter and intra laboratory studies were carried out over a period of two months by using the same chromatographic parameters. All the obtained results showed acceptable changes in the $R_{f}$ values of both the selected analytes.

Robustness: The robustness of the method was examined by slightly changing three different parameters i.e. room temp- 


\begin{tabular}{ccc|cc}
\hline \multicolumn{5}{c}{ TABLE-2 } \\
& \multicolumn{2}{c}{ REPEATABILITY ANALYSIS OF } \\
THE DEVELOPED TLC METHOD \\
\hline \multirow{3}{*}{ Run } & \multicolumn{2}{c}{ Intraday } & \multicolumn{2}{c}{ Inter day } \\
\cline { 2 - 5 } & $\begin{array}{c}\text { Albendazole } \\
\left(\mathrm{R}_{\mathrm{f}}\right)\end{array}$ & $\begin{array}{c}\text { Ivermectin } \\
\left(\mathrm{R}_{\mathrm{f}}\right)\end{array}$ & $\begin{array}{c}\text { Albendazole } \\
\left(\mathrm{R}_{\mathrm{f}}\right)\end{array}$ & $\begin{array}{c}\text { Ivermectin } \\
\left(\mathrm{R}_{\mathrm{f}}\right)\end{array}$ \\
\hline 1st & 0.67 & 0.38 & 0.67 & 0.31 \\
2nd & 0.61 & 0.40 & 0.70 & 0.42 \\
3rd & 0.65 & 0.37 & 0.61 & 0.37 \\
4th & 0.70 & 0.40 & 0.61 & 0.32 \\
5th & 0.64 & 0.35 & 0.72 & 0.48 \\
Mean \pm SD & $0.65 \pm 0.03$ & $0.38 \pm 0.02$ & $0.66 \pm 0.05$ & $0.38 \pm 0.07$ \\
\hline
\end{tabular}

erature, chamber saturation time and the ratio of mobile phase composition. The results shown in Table- 3 indicates that the selected factors were unaffected by the slight variations made in the above mentioned parameters.

\begin{tabular}{lccc}
\multicolumn{4}{c}{ TABLE-3 } \\
\multicolumn{4}{c}{ ROBUSTNESS EVALUATION OF } \\
THE DEVELOPED TLC METHOD \\
\hline Chromatographic changes & Level & $\begin{array}{c}\text { Albendazole } \\
\left(\mathrm{R}_{\mathrm{f}}\right)\end{array}$ & $\begin{array}{c}\text { Ivermectin } \\
\left(\mathrm{R}_{\mathrm{f}}\right)\end{array}$ \\
\hline Room temp. $\left({ }^{\circ} \mathrm{C}\right)$ & & \\
24 & -1 & 0.59 & 0.32 \\
25 & 0 & 0.65 & 0.38 \\
26 & +1 & 0.75 & 0.41 \\
Mean \pm SD & & $0.66 \pm 0.08$ & $0.37 \pm 0.05$ \\
\hline Chamber saturation time $(\mathrm{min})$ & & & \\
9 & -1 & 0.62 & 0.34 \\
10 & 0 & 0.65 & 0.38 \\
11 & +1 & 0.68 & 0.4 \\
Mean \pm SD & & $0.65 \pm 0.03$ & $0.37 \pm 0.03$ \\
\hline Mobile phase* composition $(\mathrm{v} / \mathrm{v} / \mathrm{v})$ & & \\
3:7:0.05 & -0.05 & 0.62 & 0.33 \\
3:7:0.1 & 0 & 0.65 & 0.38 \\
3:7:0.15 & +0.05 & 0.7 & 0.42 \\
Mean \pm SD & & $0.66 \pm 0.04$ & $0.38 \pm 0.05$ \\
\hline * Only glacial acetic acid. & &
\end{tabular}

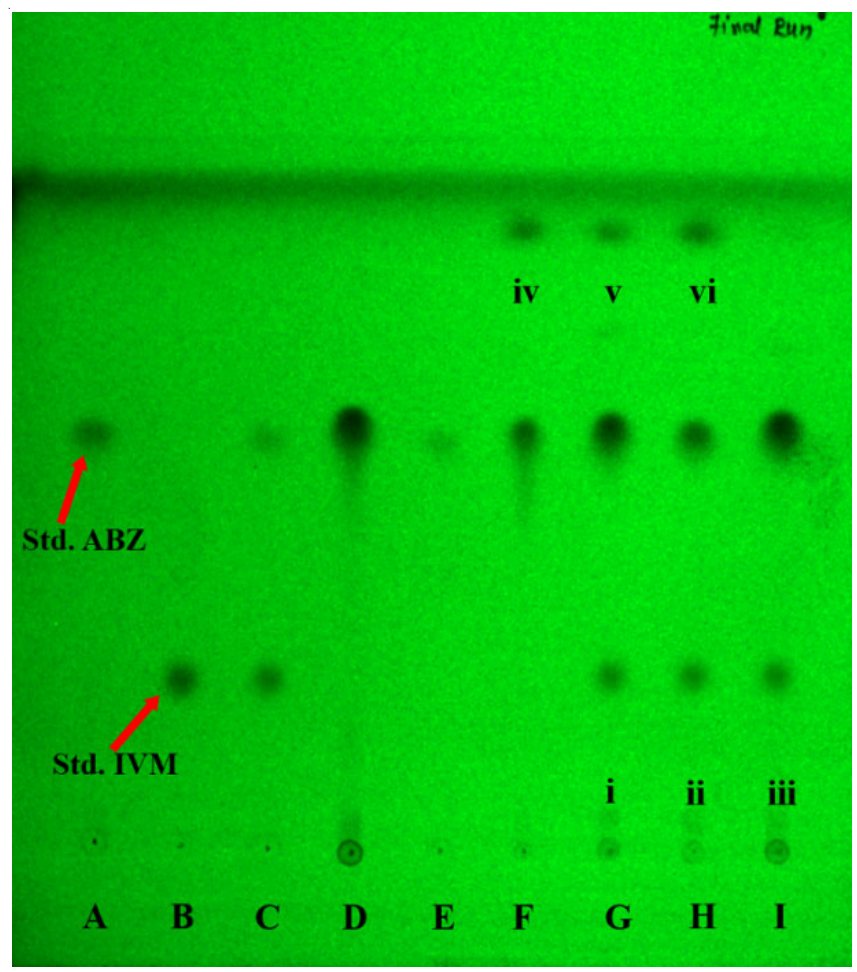

Fig. 1. Spot A-Standard ABZ, B-Standard IVM, C-Mix. of standard ABZ and IVM,D- tablet containing ABZ, E-Powder containing ABZ, FOral suspension containing ABZ, G-Oral suspension containing $\mathrm{ABZ}$ and IVM, H-Oral suspension containing ABZ and IVM, ITablet containing ABZ and IVM. Spot i-vi: excipients, colourants and other ingredients present in the pharmaceutical dosage forms

mental analysis. This developed method can be useful in the drug testing laboratories for checking the adulteration or contamination of the compounds of these classes. Apart from this, it can be ominously used in the forensic science laboratories, chemical synthesis laboratories, pharmaceutical quality control laboratories for the screening of albendazole and ivermectin.

Applications: This developed method was successfully applied for the simultaneous determination of albendazole and ivermectin in different pharmaceutical preparation such as tablets, oral suspensions, injections and powder forms of the single and combined dosage forms used as anthelmintic agents in human and veterinary medicine. The developed thin layer chromatogram (Fig. 1) shows the separation of both the analytes in different formulations.

\section{Conclusion}

In the present research work, a precise, selective, sensitive and a robust screening method for the simultaneous screening of albendazole and ivermectin has been developed and validated. As per the obtained results and their comparative study, diisopropyl ether:ethyl acetate:glacial acetic acid (7:3:0.1 v/v) at $\mathrm{pH} 3.5$ was found to be the best optimum mobile phase. The LOD was found to be $25 \mu \mathrm{g} / \mathrm{mL}$ and $30 \mu \mathrm{g} / \mathrm{mL}$ for albendazole and ivermectin, respectively. Based on the performance, selectivity and the obtained sensitivity, this developed method can be used for the screening of these compounds in pharmaceutical preparations either in different combined dosage forms or as individual compound prior to other sophisticated instru-

\section{ACKNOWLEDGEMENTS}

One of the authors (RPP) is thankful to University Grants Commission (UGC), New Delhi (India) for providing the Senior Research Fellowship and also another author (PM) is thankful to MPCOST, Bhopal, India for providing Junior Research Fellowship. The authors are also thankful to SIC of University and Department of Science \& Technology for awarding the Department with FIST Project.

\section{CONFLICT OF INTEREST}

The authors declare that there is no conflict of interests regarding the publication of this article.

\section{REFERENCES}

1. M. Alvinerie, J.F. Sutra, P. Galtier and P.L. Toutain, Ann. Rech. Vet., 18, 269 (1987).

2. P. Jedziniak, T. Szprengier-Juszkiewicz and M. Olejnik, J. Chromatogr. A, 1216, 8165 (2009);

https://doi.org/10.1016/j.chroma.2009.07.036.

3. M.A. García-Mayor, R.M. Garcinuño, P. Fernández-Hernando and J.S. Durand-Alegría, J. Chromatogr. A, 1122, 76 (2006); https://doi.org/10.1016/j.chroma.2006.04.019. 
4. F.L.D. Pontes, R. Pontarolo, F.R. Campos, J.C. Gasparetto, M.A. Cardoso, M.S. Piantavini and A.C.L.B. Trindade, Asian J. Pharm. Clin. Res., 6, 191 (2013).

5. R. Yamada, M. Kozono, T. Ohmori, F. Morimatsu and M. Kitayama, Biosci. Biotechnol. Biochem., 70, 54 (2006); https://doi.org/10.1271/bbb.70.54

6. D. García-Gómez, M. García-Hernández, E. Rodríguez-Gonzalo and R. Carabias-Martínez, Anal. Bioanal. Chem., 404, 2909 (2012); https://doi.org/10.1007/s00216-012-6415-7.

7. Y. Santaladchaiyakit, S. Srijaranai and R. Burakham, FoodAnal. Methods, 7, 1973 (2014) https://doi.org/10.1007/s12161-014-9838-2.

8. M. Bistoletti, L. Moreno, L. Alvarez and C. Lanusse, Food Chem., 126, $793(2011)$ https://doi.org/10.1016/j.foodchem.2010.11.084

9. A.C. Tella, O.M. Olabemiwo, M.O. Salawu and G.K. Obiyenwa, Int. J. Phys. Sci., 5, 379 (2010).

10. S. Varghese, P. Vasanthi and T. Ravi, J. Planar Chromatogr-Mod. TLC, 24, 344 (2011) https://doi.org/10.1556/JPC.24.2011.4.13.

11. A. Waldia, S. Gupta, R. Issarani and B.P. Nagori, Indian J. Chem. Technol., 15, 617 (2008).
12. Y. Santaladchaiyakit and S. Srijaranai, Food Anal. Methods, 6, 1551 (2013); https://doi.org/10.1007/s12161-013-9569-9.

13. A.K. Patel, H.V. Joshi and J.K. Patel, Indian J. Drugs, 3, 57 (2015).

14. M.L.G. Pérez, R. Romero-González, J.L.M. Vidal and A.G. Frenich, J. Sep. Sci., 36, 1223 (2013); https://doi.org/10.1002/jssc.201201003

15. D. Ortelli, E. Cognard, P. Jan and P. Edder, J. Chromatogr. B Analyt. Technol. Biomed. Life Sci., 877, 2363 (2009); https://doi.org/10.1016/j.jchromb.2009.03.006.

16. J.L. Martínez Vidal, A.G. Frenich, M.M. Aguilera-Luiz and R. RomeroGonzález, Anal. Bioanal. Chem., 397, 2777 (2010); https://doi.org/10.1007/s00216-009-3425-1.

17. P. Mishra, A. Durgbanshi and R.P. Pawar, Asian J. Chem., 29, 1583 (2017); https://doi.org/10.14233/ajchem.2017.20590.

18. B. Polak and A. Rompala, Acta Chromatogr., 18, 24 (2007);

19. https://www.chromacademy.com/chromatography-pH-importanceHPLC-buffers.html. 